Е. Н. Каткова

Алурский гуланитарно-педагогический государственный университет, Колсолольск-на-Алуре, Российская Федерация

Г. П. Жиганова

Алурский гуланитарно-педагогический государственный университет, Колсолольск-на-Алуре, Российская Федерация

А. А. Саяпина

Алурский гуманитарно-педагогический государственный университет, Колсолольск-на-Алуре, Российская Федераиия

\title{
ВОПРОСЫ РАЗРАБОТКИ МЕТОДОВ ДИАГНОСТИКИ СПЕЦИАЛЬНЫХ СПОСОБНОСТЕЙ К ОВЛАДЕНИЮ ИНФОРМАЦИОННЫМИ ТЕХНОЛОГИЯМИ
}

\begin{abstract}
АНнотАция. В статье обозначена актуальность исследования специальных способностей человека к овладению информационными технологиями в связи с современными требованиями общества и принципами знаниевой экономики. Теоретический анализ проблемы обнаружил отсутствие четких теоретических положений относительно структуры исследуемых способностей, а также методов их диагностики. Авторами дана формулировка определения изучаемых способностей, а также психологические основания развития способностей к овладению информационными технологиями как специальных. В рамках данной статьи представлены результаты апробации метода комплексной диагностики обучающихся в области информатики и специальных учебных дисциплин - нейронная сеть «Нейронный газ», обучаемый без исследователя, на основе автоматического кластерного анализа. Данный метод позволяет проводить массовые обследования испытуемых с целью дальнейшей сортировки их на уровни усвоения учебного материала. Метод «Нейронный газ» может применяться в других исследованиях, в зависимости от содержания заложенных критериев для кластерной сортировки. Обозначены дальнейшие перспективы изучения у студентов специальных способностей к овладению информационными технологиями и вопросы их развития в условиях вузовского образования.

кЛЮЧЕВЫЕ сЛОВА. Общие способности; специальные способности к овладению информационными технологиями; информация; методы диагностики способностей; информационные ресурсы; развитие способностей обучающихся

ИНФОРМАЦИЯ О СТАТЬЕ. Дата поступления 30 ноября 2017 г.; дата принятия к печати 19 марта 2018 г.; дата онлайн-размещения 09 апреля 2018 г.
\end{abstract}

E. N. Katkova

Amur Humanitarian Pedagogical State University, Komsomolsk-on-Amur, Russian Federation

G. P. Zhiganova

Amur Humanitarian Pedagogical State University, Komsomolsk-on-Amur, Russian Federation

A. A. Sayapina

Amur Humanitarian Pedagogical State University, Komsomolsk-on-Amur, Russian Federation

\section{ISSUES OF DEVELOPING DIAGNOSTIC METHODS FOR SPECIAL ABILITIES OF MASTERING INFORMATION TECHNOLOGIES}

ABSTRACT. The article defines the urgency of studying the human special abilities in mastering information technologies in terms of modern requirements of the society and

\section{Baikal Research Journal}


the principles of the knowledge economy. Theoretical analysis of the problem reveals the absence of clear theoretical positions regarding the structure of the investigated abilities, as well as the methods of their diagnostics. The authors give a definition of the studied abilities, as well as psychological grounds for developing abilities in mastering information technologies as the special ones. This article presents the results of approbation of the method of students' complex diagnostics in the field of computer science and special educational disciplines - the neural network «Neuron gas», trained without a researcher on the basis of an automatic cluster analysis. This method allows conducting mass examinations of the subjects in order to sort them further into the levels of mastering the educational material. The method «Neural gas» can be used in other studies, depending on the content of the initial criteria for a cluster sorting. The article indicates further prospects of studying students' special abilities in mastering information technologies and the issues of their development in terms of university education.

KEYWORDS. General abilities; special abilities in mastering information technologies; information; methods of diagnosing abilities; information resources; development of students' abilities.

ARTICLE INFO. Received November 30, 2017; accepted March 19, 2018; available online April 09, 2018.

Многие авторы подчеркивают особую роль информационных технологий в нашем постиндустриальном обществе, развитие знаниевой экономики в информационном пространстве (Журавлева Г.П., Рачков М. П., Э. Тоффлер и др.) и сегодняшние требования к современному человеку, специалисту, независимо от рода профессиональной деятельности $[1 ; 2]$. Остается открытым вопрос качества подготовки студентов в системе высшего образования. Принципы обучения, заложенные в стандартах третьего поколения, ориентированы на усвоение общекультурных и профессиональных компетенций, однако частая смена ГОС, ФГОС, министров образования, смена установок и документов от минобрнауки, все это привносит в систему образования смуту, поскольку не понятно, каким образом внедрять компетентностный подход и отслеживать его эффективную реализацию. Обычные преподаватели университета не успевают за сменой учебных стандартов и распоряжений, поэтому в такой динамичной ситуации постоянной остаётся классическая задача развития способностей студентов в учебной деятельности, так как именно они обеспечивают личности успешность в освоении профессионального образования независимо от особенностей учебных стандартов и спускаемых сверху распоряжений от министерства образования.

Ещё В. П. Тихомиров в своих работах указывал на то, что человек информационного общества создаёт, прежде всего, новые знания. «Задача университетов все более состоит в том, чтобы не просто передавать своим студентам имеющийся набор знаний, пусть самых современных и востребованных, не только выпускать специалистов в какой-либо области, которые хорошо подготовлены и много знают. Нужно не только научить студентов извлекать знания из моря данных и информации, которая находится сегодня в интернете, в других хранилищах и библиотеках. В рамках информационного общества этого недостаточно. Университет должен научить знания создавать. А для этого необходимо все большее сращивание учебной и научной сторон деятельности университетов, усиленный поиск творчески одаренной молодежи, стимулирование ее интереса к науке и творчеству, развитие ее способностей. Информационные и коммуникационные технологии (ИКТ) создают для такого поиска неограниченные, ранее небывалые возможности. Сегодня новому Ломоносову не нужно с рыбным обозом идти в Москву - достаточно войти в интернет!» $[3$, с. 1$]$.

\section{Baikal Research Journal}


В наших ранних научных работах мы уже поднимали эту проблему [4]. Мы считаем, что данную противоречивую ситуацию спасёт разработка системы психологической диагностики способностей студентов к овладению информационными технологиями. Реализация данной идеи в практике функционирования университета требует системного подхода, который предполагает рассмотрение предмета психологического исследования как целостной и многомерной реальности, а именно решение теоретической проблемы уточнения структуры специальных способностей к овладению IT-технологиями и практической реализации задач их диагностики и мониторинга.

Современное информационное общество, по мнению Э. Тоффлера и Е.Н. Рябовой, требует от современного человека новых умений и навыков, которые реализуются в трех ключевых направлениях: умение учиться, умение общаться и умение выбирать (см. табл. 1).

Таблица 1

Ключевые умения современного человека по Э. Тоффлеру [2] и Е.Н. Рябовой [5]

\begin{tabular}{|c|c|c|}
\hline Умение учиться & Умение общаться & Умение выбирать \\
\hline $\begin{array}{l}\text { В современном информаци- } \\
\text { онном обществе информация } \\
\text { устаревает очень быстро, ее } \\
\text { необходимо постоянно обнов- } \\
\text { лять. Поэтому школа будущего } \\
\text { должна не только "вкладывать } \\
\text { в голову» обучаемого некий } \\
\text { массив знаний, но и учить им } \\
\text { оперировать. } \\
\text { Необходимо научиться вовре- } \\
\text { мя отказываться от устарев- } \\
\text { ших идей, а также тому, как } \\
\text { и когда их заменять, то есть } \\
\text { школьники должны «научиться } \\
\text { учиться». } \\
\text { «Новое образование должно } \\
\text { научить индивида, как клас- } \\
\text { сифицировать и перекласси- } \\
\text { фицировать информацию, как } \\
\text { оценивать ее достоверность, как } \\
\text { при необходимости изменять } \\
\text { категории, как переходить от } \\
\text { конкретного к абстрактному, и } \\
\text { наоборот, как взглянуть на про- } \\
\text { блемы под новым углом зрения, } \\
\text { как заниматься самообразова- } \\
\text { нием. Неграмотным в будущем } \\
\text { будет не тот человек, который } \\
\text { не умеет читать, а тот, кто не } \\
\text { научился учиться» [2, с. } 451]\end{array}$ & $\begin{array}{l}\text { Tемп жизни постоянно возрас- } \\
\text { тает, а значит, увеличивается и } \\
\text { количество коммуникативных } \\
\text { контактов каждого человека. У } \\
\text { многих людей, особенно под- } \\
\text { ростков и молодежи, возникают } \\
\text { трудности в установлении и под- } \\
\text { держании полезных контактов с } \\
\text { другими людьми. Особенно это } \\
\text { касается тех, кто предпочитает } \\
\text { общение в виртуальном мире (в } \\
\text { социальных сетях Интернета, } \\
\text { в чатах, на форумах). У таких } \\
\text { людей могут возникать большие } \\
\text { проблемы в сфере реальной, } \\
\text { а не виртуальной коммуника- } \\
\text { ции (дружба, любовь, создание } \\
\text { семьи). } \\
\text { Роль образования здесь двой- } \\
\text { ственна: либо оно должно } \\
\text { помогать людям мириться с } \\
\text { отсутствием глубокой дружбы, } \\
\text { с одиночеством и недоверием, } \\
\text { либо каким-то образом учить нас } \\
\text { общению, новым способам завя- } \\
\text { зывать дружеские отношения в } \\
\text { кратчайшие сроки, организуя } \\
\text { группы учащихся с творческим } \\
\text { воображением или трудовые } \\
\text { коллективы нового типа }\end{array}$ & $\begin{array}{l}\text { Информационное обще- } \\
\text { ство предоставляет ин- } \\
\text { дивиду, расширенный } \\
\text { спектр возможностей } \\
\text { для выбора в самых } \\
\text { различных сферах, тем } \\
\text { самым повышая слож- } \\
\text { ность принимаемых } \\
\text { индивидом решений. } \\
\text { Поэтому образование } \\
\text { должно уделять внима- } \\
\text { ние и проблеме чрез- } \\
\text { мерно богатого выбора, } \\
\text { учить человека делать } \\
\text { выбор, совпадающий с } \\
\text { его системой ценностей, } \\
\text { а значит, «помогать } \\
\text { учащимся определить, } \\
\text { развить и проверить } \\
\text { свои ценностные ориен- } \\
\text { тации» [5, с. 75] }\end{array}$ \\
\hline
\end{tabular}

В связи с этими задачами развития общества, безусловно требуется рассмотрение психологии способностей студентов, которые определяют их успешность в учебной деятельности. Наш научный коллектив, работая на факультете информационных технологий математики и физики АмГПГУ, предпринял попытку изучения структуры специальных способностей к овладению информационными технологиями в рамках профессиональных и общекультурных компетенций, заложенных в ФГОС. Данная компетенция очень важна для современного человека, так как по оценкам многих ученых в области информатики, каждые 5-6 лет в

\section{Baikal Research Journal}


мире кардинально меняются информационные технологии и способы их применения, при этом люди с разной успешностью усваивают IT-технологии. Даже современный учитель, плохо владеющий информационными технологиями, не востребован как специалист в сегодняшней школе.

Компетенция «Овладение информационными технологиями» входит в базовый уровень образования всех направлений подготовки в системе высшего образования, обобщая различные текстовые формулировки по учебным планам различных направлений, данная формулировка выглядит примерно следующим образом: способен использовать в своей профессиональной деятельности современные компьютерные, информационные и телекоммуникационные технологии. Она включена в блок профессиональных компетенций. В целом IT-технологии классифицируются на виды, и по основанию реализуемых технологических операций их можно разделить следующим образом [6]:

- технология работы с текстовым процессором;

- технология работы с табличным процессором;

- технология работы с системой управления базами данных (СУБД);

- технология работы с графическими объектами;

- мультимедиатехнология;

- гипертекстовая технология;

- технология обеспечения обратной связи посредством компьютера;

- технология использования Internet.

Что касается направлений подготовки со специализированным профессиональным изучением информационных технологий на факультете информационных технологий математики и физики АмГПГУ, то в разделах ФГОС требования к знаниям, умениям и навыкам гораздо глубже и шире. Если мы откроем стандарты ФГОС, то увидим, что формулировка способностей носит общий характер, фактически понятие «способности», используется и трактуется авторами стандарта очень вольно и порой некорректно.

Обращаясь к основным положениям психологии способностей, мы находим основное базовое определение способностей в трудах классика отечественной психологии Б. М. Теплова, по его мнению, это индивидуально-психологические свойства личности, не сводящиеся к знаниям, умениям и навыкам, и определяющие быстрое, легкое, глубокое и успешное овладение какой-либо деятельностью [7]. Во ФГОС способности как раз и свели к пресловутым знаниям, умениям и навыкам. В связи с этим мы подвергли теоретическому анализу психологическую сущность способностей, подходы, классификации, с целью определения феномена специальных способностей по овладению информационными технологиями.

На сегодняшний день многие авторы пользуются общей трактовкой, фактически превращая на понятийном уровне способности человека в компетенцию, которая представлена как компетенция по овладению информационными технологиями, и обозначается она как информационная компетенция. Ряд авторов даёт конкретные определения именно информационной компетенции. Так, О. Б. Зайцева [8, с. 14], определяет её как «сложное индивидуально-психологическое образование на основе интеграции теоретических знаний, практических умений в области инновационных технологий и определённого набора личностных качеств». А. Л. Семенов в свою очередь, [9, с. 32] трактует её как «новую грамотность, в состав которой входят умения активной самостоятельной обработки информации человеком, принятие принципиально новых решений в непредвиденных ситуациях с использованием технических средств». С. В. Тришина [10] определяет информационную компетенцию как «интегративное качество личности, являющегося результатом отражения процессов отбора, усвоения, переработки, транс-

\section{Baikal Research Journal}


формации и генерирования информации в особый тип предметно-специфических знаний, позволяющее вырабатывать, принимать, прогнозировать и реализовывать оптимальные решения в различных сферах деятельности». О. Н. Грибан [11, c. 184-186] связывает информационную компетенцию «со знаниями и умениями работы с информацией на основе новых информационных технологий и решением повседневных учебных задач средствами НИТ».

В связи с выше приведёнными положениями некоторых авторов, по нашему мнению, требуется обязательное рассмотрение психологии общих учебных способностей субъекта применительно к структуре специальных способностей к овладению информационными технологиями. Кафедра психологии образования АмГПГУ занималась исследованием психологии способностей на протяжении 1998-2015 гг. Так, Шмакова В. А. [12], исследуя учебные способности субъекта, указывает на то, что учебная деятельность субъектно-ориентирована и это отличает ее от других видов деятельности и успешное освоение такой деятельностью связано с потребностью в социализации посредством постоянного преобразования себя. Успешность деятельности предопределяется отношением человека к ней. На основе позитивного отношения к предмету деятельности происходит формирование системы способов достижения значимых для человека целей. А учебные способности являются внутренними условиями, обеспечивающие успешное овладение учебной деятельностью

Шмакова В.А. [12] определяет учебные способности как сложные способности, в структуру которых входят «индивидуально-психологические особенности личности, характеризующие учащегося как субъекта общественно-значимой деятельности». Личностные свойства, которые определят успешность учебной деятельности, должны отражать субъектное отношение к учебной деятельности. Содержательную сторону учебной деятельности составляют знания. Содержанием знаний являются научные понятия.

Ряд авторов отмечают, что в процессе культурно-исторического развития происходит формирование специальных способностей, отражающих общественную потребность в специализации деятельности. В частности, Волкова Е. В., изучая химические специальные способности, отмечает в своих трудах идею о том, что принцип развития в специальных способностях осуществляется через переход от минимально дифференцированных ментальных структур к детально дифференцированным и одновременно интегрированным. $K$ примеру, можно выделить индикатор времени реакции человека в ситуации сложного выбора, который в свою очередь и приводит к развитию ментальных структур. Индикатор обучения субъекта с учётом развития специальных способностей даёт их высокие показатели по сравнению с обучением, игнорирующим эти закономерности развития [13].

Каткова Е. Н., опираясь на работы отечественных классиков $[7 ; 14]$ и собственные эмпирические исследования по психологии комбинаторных способностей [15-18] предприняла попытку теоретического рассмотрения структуры специальных способностей к овладению информационными технологиями. Наша группа авторов, исходя из ранее проведенных исследований, предположила, что специальные способности к овладению информационными технологиями являются индивидуально-психологическими свойствами, обеспечивающие чувствительность и устойчивый интерес к IT-технологиям, и определяющие успешное и самостоятельное их освоение субъектом деятельности в соответствии с тенденциями научно-технического прогресса в обществе.

Специальные способности развиваются на базе высокого уровня развития общих способностей человека. По данным Волковой Е. В. [13], мы можем констатировать, что по мере роста специальных способностей идет ослабление связей

\section{Baikal Research Journal}


между показателями общих и специальных способностей. Когда достигается определенное пороговое значение - связи среди показателей специальных и общих способностей имеют свойство разрушаться, и таким образом возникает новое автономное психическое образование, которое называется специальными способностями. На основе этого можно заключить, что ведущим фактором в развитии специальных способностей к овладению информатикой может выступать когнитивная дифференцированность и высокая интегрированность концептуальных структур, референтных области IT-технологий.

Овладение информационными технологиями студентами связано с их будущей профессиональной деятельностью в системе «человек-машина». Операторская деятельность человека сформировалась в современном обществе как особый вид деятельности, связанный с достижениями научно-технического прогресса, а именно с развитием технических компьютеризированных систем и проблемой управления ими. Информационные технологии в свою очередь представляют собой разнообразие программных продуктов, которые загружаются в машину-компьютер. Освоение программного продукта человеком предполагает процесс приёма, переработки информации, принятия решения и выполнение им управляющих воздействий в ситуации дефицита времени.

Теоретически рассматривая структуру специальных способностей к овладению информационными технологиями мы должны обратится к поиску природных предпосылок (задатков), при этом выраженность того или иного физиологического качества влияет на развитие специальных способностей как благоприятный фактор только в условиях целенаправленной учебной деятельности по овладению IT-технологиями. К задаткам способностей можно отнести типологические свойства, отражающие индивидуальные особенности функционирования психики и организма: пределы работоспособности, скорость нервной реакции, перестройка реакции в ответ на изменение внешних воздействий. Данные характеристики нужно учитывать при отборе диагностических методик, направленных на выявление развития специальных способностей по овладению IT-технологиями.

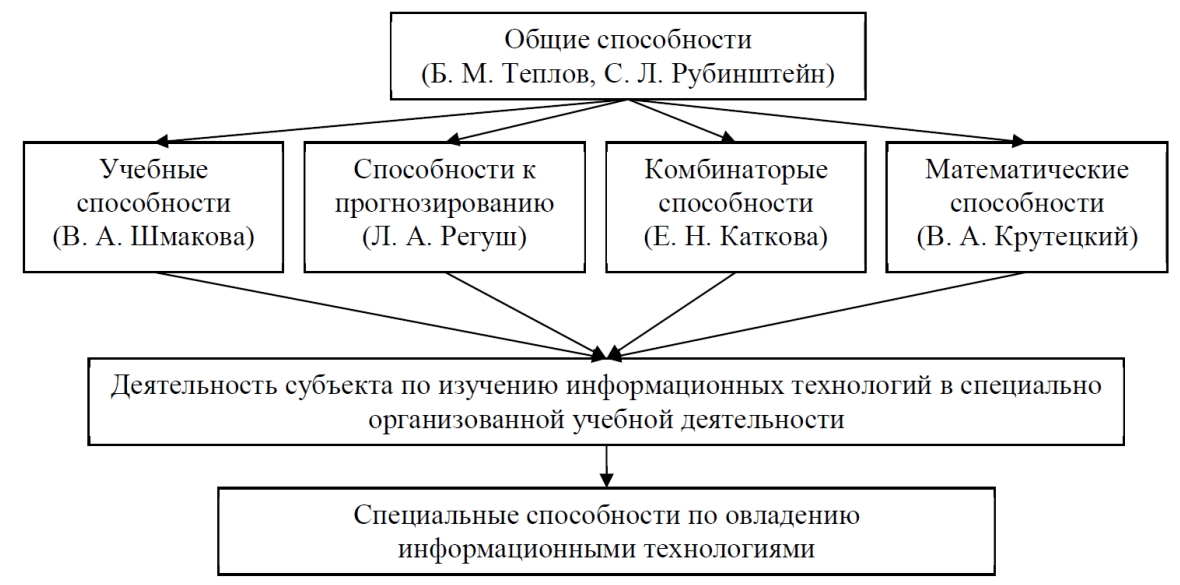

Рис. 1. Механизм зарождения специальных способностей к овладению Іт-технологияли на основе развития общих способностей в деятельности субъекта по изучению IT-технологий

Развитие специальных способностей обусловлено специализированной деятельностью, в нашем случае это учебная деятельность студентов, как правило,

\section{Baikal Research Journal}


на занятиях по информатике, а также на других спецпредметах, предполагающих изучение информационных технологий. В рамках методологии С. Л. Рубинштейна, Б. М. Теплова, В. А. Шмаковой, Л. А. Регуш и В. А. Крутецкого мы можем ориентировочно сформулировать следующее определение способностей к овладению IT-технологиями: это индивидуально-психологические особенности умственной деятельности субъекта, отвечающие требованиям учебной деятельности и ЗУНов в области информатики, обуславливающие на прочих равных условиях успешность творческого и самостоятельного овладения информатикой как учебным предметом, а именно относительно быстрое, легкое и глубокое овладение областью информационных технологий. На рис. 1 представлена наша структурная модель возникновения специальных способностей к овладению информационными технологиями.

Мы предлагаем следующую модель структуры специальных способностей к овладению IT-технологиями:

1) устойчивый интерес к IT-технологиям;

2) отличная реакция в работе с операционными механизмами компьютера;

3) высокая работоспособность в обработке информации;

4) быстрая обучаемость;

5) высокий уровень распределения внимания;

6) высокий уровень обобщения;

7) эффективность принятия решений в диалоге с компьютером, прогнозирование результатов и последствий;

8) чувствительность к сигналам обратной связи;

9) когнитивный перенос умения в новые обстоятельства;

10) комбинаторно-творческая переработка информации и самостоятельное создание новых IT-технологий.

Мы разработали компьютерную программу мониторинга успешности усвоения студентами учебной программы по овладению информатикой на факультете информационных технологий, математики и физики. Успешность студентов по овладению знаниями, умениями и навыками в области информатики в системе образования обычно определяется их успеваемостью по спецпредметам. Целью данного мониторинга является использование его результатов по отбору успешных студентов-первокурсников по базовой дисциплине «Информатика» до начала узкоспециализированного профессионального обучения.

В апробации программы мониторинга приняли участие студенты факультета ФИТМиФ АмГПГУ 2013, 2014, 2015 гг. выпуска, в количестве 175 человек. Выпускники 2013 года ( $n=79)$, обучались по направлениям: «Бизнес-Информатика», «Математика-Английский язык», «Математика-Экономика», «Математика-Информатика», «Информационные системы»; студенты 2014 года выпуска $(n=46)$ - «Бизнес-Информатика», Информатика-Английский язык», «Математика-Информатика». "Математика-Экономика», «Математика и Компьютерные науки»; студенты 2015 года выпуска $(n=50)$ - «Информационная безопасность», «Информационные системы», «Математика и Компьютерные науки» .

Мы разработали, интеллектуальную систему, которая позволяет самостоятельно отсортировать контингент испытуемых по разноуровневым кластерам, отражающих успешность и самостоятельность обучения студентов на факультете информационных технологий, математики и физики АмГПГУ. В исследовании использовались зачётно-экзаменационные ведомости студентов по информатике: в период за 2013-2015 учебные годы, а также успеваемость по специализированным учебным предметам в области информатики. Для того, чтобы облегчить сортировку учебных предметов для кластерного анализа и отсортировать успева-

\section{Baikal Research Journal}


емость, мы условно поделили все учебные спецпредметы по нескольким направлениям: администрирование, программирование, сети, аналитика, графика. Мы исходили из того, что каждый из спецпредметов так или иначе обслуживает данные направления в информатике.

В определении уровневости успеваемости использовались рейтинговые показатели по зачетам и экзаменам. На факультете ФИТМиФ АмГПГУ используются классические университетские методы обучения: лекции, семинарские занятия, практические занятия, лабораторные работы, коллоквиумы и тестирования, а также нетрадиционные методы: активное обучение, тренинги, доклады, дискуссии, деловые игры, конкурсные проекты, мастер-классы, выходы на предприятия. В учебных программах преподаватели закладывают задачи развития личности студентов, в частности такие как, интерес к учебной деятельности, способность к самоорганизации, способность работать в команде, адекватный уровень самооценки, критичность ума, эмоциональная устойчивость, активность, креативность и настойчивость (согласно опросам преподавателей, работающих на факультете).

Оценки по курсовым и дипломным/бакалаврским работам явились уровневым критерием самостоятельности студентов. При их написании автор должен проявить навыки самостоятельных расчетов, анализа, интерпретации и обобщения теоретической и социологической информации, умение использовать литературу, фондовые источники и базы данных.

Таким образом, мы считаем, что смысл овладения информационными технологиями заключается в том, что человек может самостоятельно без посторонней помощи по аналогии освоить незнакомые ему информационные области, которые время от времени появляются вместе с ростом научно-технического прогресса, а также может стать создателем новых информационных технологий и систем.

Для кластеризации выпускников АмГПГУ ФИТМиФ нами была выбрана нейронная сеть «Нейронный газ» обучаемый без исследователя (учителя). Расширяющийся нейронный газ ${ }^{1}$ является алгоритмом, позволяющий осуществлять адаптивную кластеризацию входных данных, то есть не только разделить пространство на кластеры, но и определить необходимое их количество исходя из особенностей самих данных. Это новый класс вычислительных механизмов.

Кластерный анализ ${ }^{2}$ представляет собой многомерную статистическую процедуру, выполняющую сбор данных, содержащих информацию о выборке объектов, и затем упорядочивающую объекты в сравнительно однородные группы. Задача кластеризации относится к статистической обработке, а также к широкому классу задач обучения без исследователя (учителя).

Преимущества данного алгоритма заключаются в том, что он позволяет определить топологию входных данных без какой-либо априорной информации об этих данных. Кроме того, задавая ограничение на размер строящейся нейронной сети, можно эффективно управлять ресурсами, которые потребляет алгоритм, и временем его работы. $K$ недостаткам данного алгоритма относится то, что на его настройку влияют данные, подобрать которые оптимальным образом для конкретной задачи может оказаться непросто. Второй недостаток заключается в том, что классический алгоритм нейронного газа выдает нейронную сеть, отображающую топологию входных данных.

${ }^{1}$ Нейронный газ // Википедия. URL: https://ru.wikipedia.org/wiki/нейронныйгаз (дата обращения: 05.10 .2016$)$.

${ }^{2}$ Кластерный анализ // Википедия. URL: https://ru.wikipedia.org/wiki/кластерныйанализ (дата обращения: 05.10 .2016$)$.

\section{Baikal Research Journal}

электронный научный журнал Байкальского государственного университета 

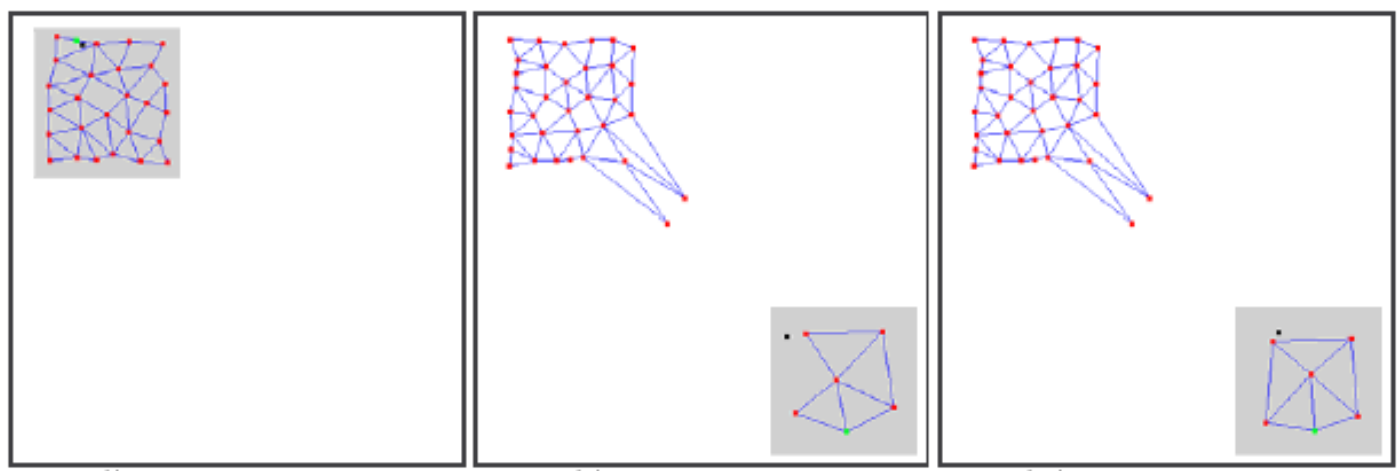

Рис. 2. Реакиия растущего нейронного газа на «прыгающее» распределение

Программисты [19], которые изучали растущий нейронный газ на языке программирования MQL5, указывают на то, что основной проблемой GNG является его неспособность отслеживать нестационарные ряды с быстро меняющимися характеристиками. Такие «прыгающие» распределения входных сигналов могут явиться причиной того, что значительная часть нейронов GNG-слоя, уже наработав определенную топологическую структуру, внезапно оказываются не у дел. Поскольку входные сигналы уже не попадают в область их расположения, возраст связей между этими нейронами не увеличивается, следовательно, «мертвая» часть сети, которая «помнит» старые характеристики сигнала, не делает полезной работы, а лишь расходует вычислительные ресурсы (см. рис. 2). Однако, как показывают практические исследования в области программирования [19-22], наличие отдельных неактивных узлов в нейронной сети в результате обучения лишь менее дифференцированно кластерирует данные, для психологического смысла подробная детализация кластеров не является столь существенной, так как наша исследовательская задача заключается в том, чтобы определить тенденции выраженности качественного признака. Алгоритм нейронного газа по Г.П. Жигановой выглядит следующим образом:

- Инициализировать 2 узла нейронной сети (из исходных данных) и соединить их связью с возрастом, равным 0. В качестве весовых коэффициентов этих узлов берутся координаты соответствующих точек.

- Подать на вход алгоритма произвольный вектор $\bar{x}$.

- Найти 2 нейрона $s$ и $t$, ближайшие к $\bar{x}$. Обычно в качестве меры расстояния выбирается Евклидова метрика, однако, в качестве меры расстояния может быть также использована мера Жаккара, косинусный коэффициент и т. д. Дальнейшее описание алгоритма будет приведено для Евклидовой меры.

- Обновить ошибку нейрона-победителя (нейрон, для которого расстояние до входного вектора $\bar{x}$ минимально)

$$
\left.E_{s}=E_{s}+\llbracket w_{s}-\bar{x}\right\rfloor^{2}
$$

где $E_{s}$ - ошибка нейрона $s, \overline{w_{s}}$ - вектор весов нейрона $s$.

- Сместить нейрон $\mathrm{s}$ и всех его соседей

$$
\begin{aligned}
& \overline{w_{s}}=\overline{w_{s}}+\varepsilon_{w}\left(\overline{w_{s}}-\bar{x}\right) \\
& \overline{w_{n}}=\overline{w_{n}}+\varepsilon_{n}\left(\overline{w_{n}}-\bar{x}\right)
\end{aligned}
$$

Где $\varepsilon_{w}, \varepsilon_{n}-$ коэффициенты обучения нейрона-победителя и его соседей соответственно. В классическом алгоритме нейронного газа они остаются постоянными

\section{Baikal Research Journal}


на протяжении всего процесса обучения. Эти параметры являются входными параметрами алгоритма, при этом обычно выбирают

$\varepsilon_{w}=100 \ldots .1000 \varepsilon_{n}$

- Увеличить на 1 возраст дуг, исходящих от $s$

- Если нейроны $s$ и $t$ соединены, то обнулить возраст их связи; если связи нет, то создать новую.

- Удалить все дуги с возрастом, превышающим $a g e_{\max }$

- Если номер итерации кратен $\lambda_{\max }$, то осуществить вставку нового узла:

- найти нейрон $u$ с максимальной локальной ошибкой

- среди соседей $u$ найти нейрон $v$ с максим альной ошибкой

- создать узел $r$ с вектором весов равным $\overline{w_{r}}=\frac{\overline{w_{u}}-\overline{w_{v}}}{2}$

- заменить связь $(u, v)$ на $(u, r)$ и $(v, r)$

- уменьшить ошибки нейронов $u$ и $v$, установить значение ошибки нейрона $r$ следующим образом:

$E_{u}=E_{u} * a$

$E_{v}=E_{v} * a$

$E_{r}=E_{u}$

- Уменьшить ошибки всех нейронов ј на долю $\beta: E_{j}=E_{j} * \beta$

- Если критерий останова не выполнен, то перейти на шаг 2.

Для решения задачи была создана программа на язык программирования Python с использованием следующих библиотек:

1) Modular toolkit for Data Processing - коллекция контролируемых и неконтролируемых алгоритмов обучения и других алгоритмов обработки данных;

2) NumPy - Коллекция вычислительных алгоритмов, оптимизированных для работы с многомерными массивами.

Модель данных была составлена по результатам выпускников за 2013-2015 год, данные были разделена по категориям:

- степень овладения общими дисциплинами (блок общеобразовательных университетских дисциплин);

- степень овладения специальными дисциплинами (спецпредметы были объединены по направлениям - администрирование, аналитика, программирование, сети, компьютерная геометрия и графика, программное обеспечение ЭВМ);

- степень самостоятельности (данные по защите курсовых и дипломных/бакалаврских работ).

Используя выше приведенный алгоритм нейронного газа, мы вычислили количество кластеров по критериям успешности и самостоятельности студентов ФИТМиФ АмГПГУ. В результате обучения «Нейронного газа» по представленным категориям и параметрам, сформулированными в табл. 3, было получено 13 классов.

Параметры обучения нейронной сети

Таблица 3

\begin{tabular}{|c|l|c|}
\hline Параметр & \multicolumn{1}{|c|}{ Описание } & Значение \\
\hline eps_b & Коэффициент движения ближайшего узла к новой точке данных & 0,2 \\
\hline eps_n & Коэффициент движения ближайшего узла к новой точке данных & 0,006 \\
\hline max_age & Удаление ребра после 'тах_аge' обновлений & 50 \\
\hline lambda & Добавление нового узла после итераций & 100 \\
\hline alpha & $\begin{array}{l}\text { Когда новый узел вставляется, умножьте ошибку узлов, из которых } \\
\text { он, порожденных 0 альфа <1 }\end{array}$ & 0,5 \\
\hline d & каждый шаг ошибка узлов умножаются $0<\mathrm{d}<1$ & 0,995 \\
\hline max_nodes & Максимальное количество узлов & 100 \\
\hline
\end{tabular}

\section{Baikal Research Journal}


$\mathrm{C}$ помощью разработанного программного продукта «Нейронный газ», полученные кластеры мы условно интерпретировали на основе количественных данных обучения нейронного газа по нашему алгоритму. В табл. 4 мы представили результаты распределения испытуемых студентов по обнаруженным нейронным газом кластерам.

\section{Количественное и качественное распределение кластеров после обучения нейронного газа}

\begin{tabular}{|c|c|c|}
\hline $\begin{array}{c}\text { Нумерация } \\
\text { кластеров }\end{array}$ & $\begin{array}{l}\text { Количество } \\
\text { студентов }(n)\end{array}$ & $\begin{array}{c}\text { Качественная интерпретация } \\
\text { кластеров }\end{array}$ \\
\hline 1 кластер & 15 & $\begin{array}{l}\text { Выпускники с очень высокими показателями по всем зало- } \\
\text { женным параметрам }\end{array}$ \\
\hline 2 кластер & 20 . & $\begin{array}{l}\text { Выпускники с низкой самостоятельностью и средним уровнем } \\
\text { освоения программы образования }\end{array}$ \\
\hline 3 кластер & 16. & $\begin{array}{l}\text { Выпускники с низким интересом к общей программе и само- } \\
\text { стоятельной работе }\end{array}$ \\
\hline 4 кластер & 50 & Выпускники со средними показателями по всем параметрам \\
\hline 5 кластер & 12 & $\begin{array}{l}\text { Самостоятельность выше среднего, освоение общей программы } \\
\text { выше среднего, высокое освоение специальной программы }\end{array}$ \\
\hline 6 кластер & 5 & $\begin{array}{l}\text { Выпускники с показателями ниже среднего по всем дисципли- } \\
\text { нам и высокой самостоятельностью }\end{array}$ \\
\hline 7 кластер & 4 & $\begin{array}{l}\text { Высокая самостоятельность, средние показатели освоения всей } \\
\text { программы образования }\end{array}$ \\
\hline 8 кластер & 8 & $\begin{array}{l}\text { Слабые выпускники по освоению всей программы образования } \\
\text { и самостоятельностью }\end{array}$ \\
\hline 9 кластер & 4 & $\begin{array}{l}\text { Выпускники со стремящимися к высоким показателям образо- } \\
\text { вания по всем параметрам }\end{array}$ \\
\hline 10 кластер & 3 & $\begin{array}{l}\text { Выпускники со слабыми показателями освоения специальных } \\
\text { дисциплин и низкой самостоятельностью. }\end{array}$ \\
\hline 11 кластер & 9 & $\begin{array}{l}\text { Выпускники со средними показателями самостоятельности и с } \\
\text { низкими показателями освоения специальных дисциплин }\end{array}$ \\
\hline 12 кластер & 23 & $\begin{array}{l}\text { Выпускники с показателями ниже среднего по освоению всех } \\
\text { дисциплин и проявлению самостоятельности }\end{array}$ \\
\hline 13 кластер & 6 & $\begin{array}{l}\text { Выпускники с очень высокими показателями самостоятельно- } \\
\text { сти, с показателями освоения общих дисциплин выше сред- } \\
\text { него и высокими показателями освоения специальных дисци- } \\
\text { плин }\end{array}$ \\
\hline
\end{tabular}

На основе количественной кластерной раскладки данных мы распределили результаты нейронного газа по уровням освоения образовательной программы студентами, принявших участие в исследовании. В данном распределении мы опирались на качественные характеристики кластерных групп (см. рис. 3).

Из рисунка 3 видно, что уровни освоения выпускниками образовательной программы на факультете информационных технологий, математики и физики в основном стремятся к показателям средним и ниже средних. Мы считаем, что это обусловлено собственной сложностью учебных спецдисциплин из области информатики и низким развитием способностей студентов.

\section{Baikal Research Journal}

электронный научный журнал Байкальского государственного университета 


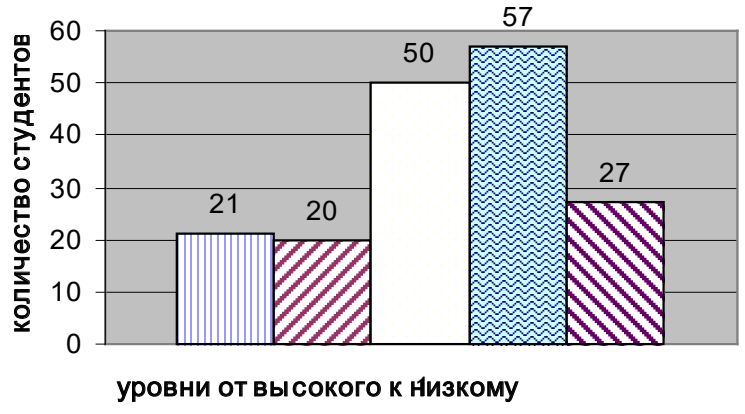

\begin{tabular}{ll}
\hline$\square$ высокий & $\square$ выше среднего \\
$\square$ средний & 园 ниже среднего/средний
\end{tabular}

$\mathbf{\nabla}$ низкий

Рис. 3. Количественное распределение студентов на уровни по объединенныл кластерал: высокий уровень - 1, 13 кластеры; выше среднего - 5, 7, 9 кластеры; средний - 4 кластер; ниже среднего/средний - 2, 6, 11, 12 кластеры; низкий уровень - 3, 8, 10 кластерь.

Также мы произвели сравнительные расчеты распределения испытуемых студентов по годам выпуска (см. рис. 4), в процессе качественного сравнения мы увидели, что в 2014 году показателей высокого уровня образования и самостоятельности было гораздо больше. Кроме этого опрос преподавателей спецдисциплин показал, что студенты 2014 года выпуска, по их мнению, были более «способными и интересными», преподаватели общих дисциплин, не работающих на кафедрах ФИТМиФ, легко смогли вспомнить фамилии, по их словам, «студентов-звёзд», в отличие от выпускников 2013 и 2015 годов.

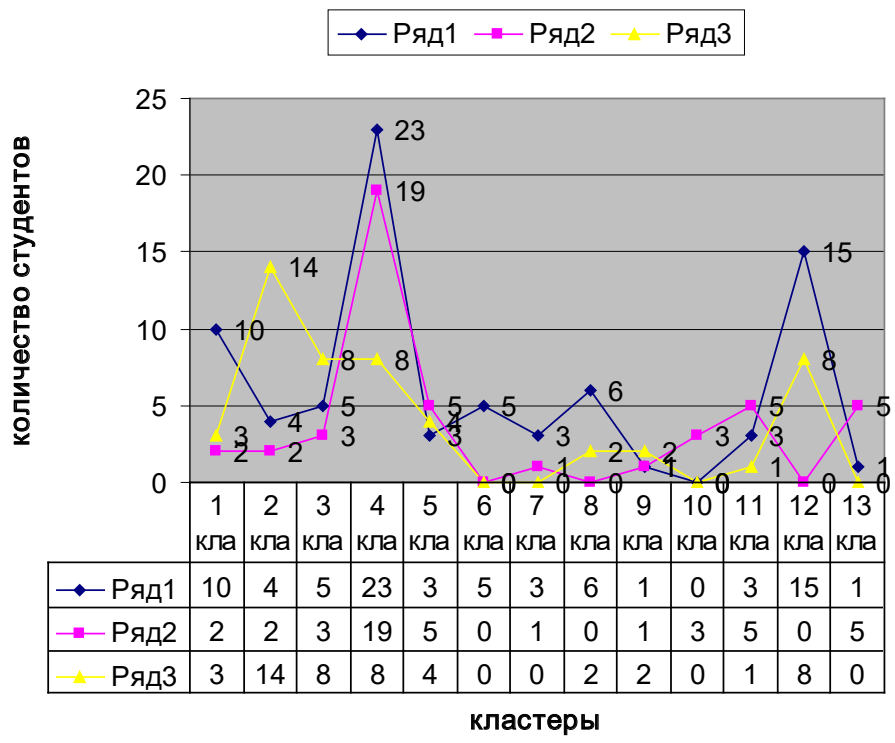

Рис. 4. Распределение студентов на кластеры по годам выпуска: ряд 그 1 - 2013 год, ряд № $2-2014$ год, ряд № $3-2015$ год

\section{Baikal Research Journal}


Подводя итоги диагностики с помощью «Нейронного газа» и проанализировав полученные качественные характеристики, мы решили обобщить полученные данные на три крупные группы и произвести сравнительный анализ результатов обследования испытуемых студентов разного года выпуска. В первую группу с высокими и выше средних характеристиками вошли кластеры № $1,5,7,9,13$; во вторую группу со стабильными средними характеристиками вошел кластер № 4; в третью группу с низкими характеристиками и ниже средних вошли кластеры № $2,3,6,8,10,11,12$ (см. рис. 5).

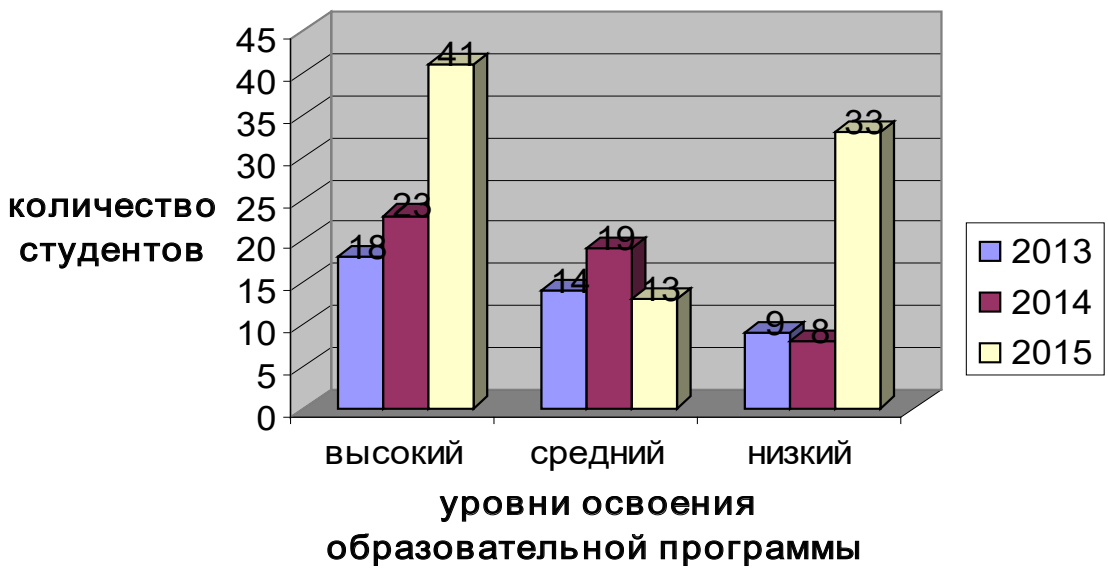

Рис. 5. Количественное сравнительное распределение студентов разного года выпуска из университета по объединенным кластерам на три уровневые группы

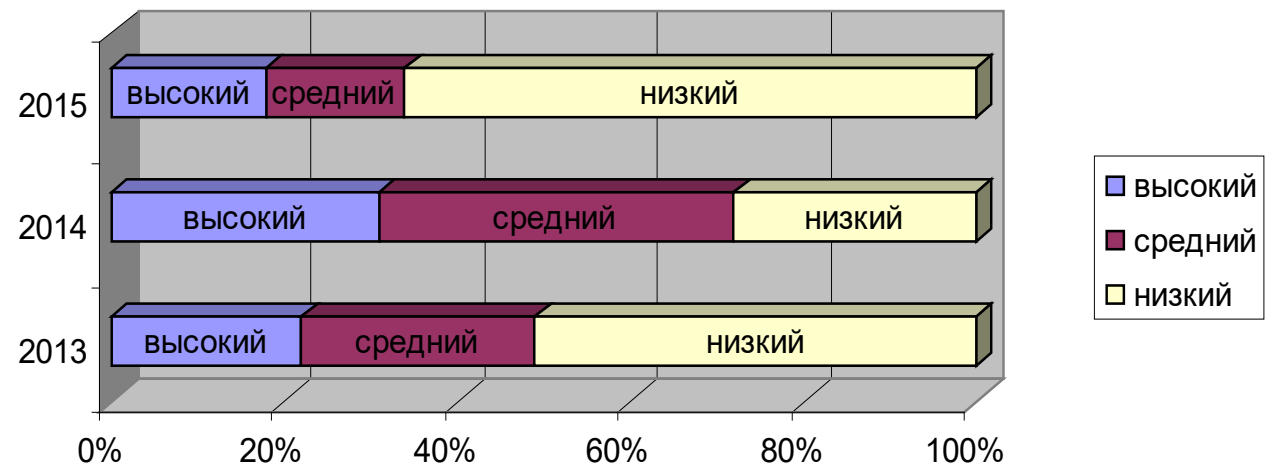

Рис. 6. Процентное распределение студентов по уровням освоения учебной програмлы университета разных годов выпуска.

Для того, чтобы посмотреть качественную динамику изменения показателей усвоения учебного материала студентами факультета информационных технологий математики и физики разных годов выпуска, мы перевели в процентное соотношение полученные данные (см. рис. 6 и 7) и применили статистическое сравнение по критерию Фишера (см. табл. 5).

\section{Baikal Research Journal}



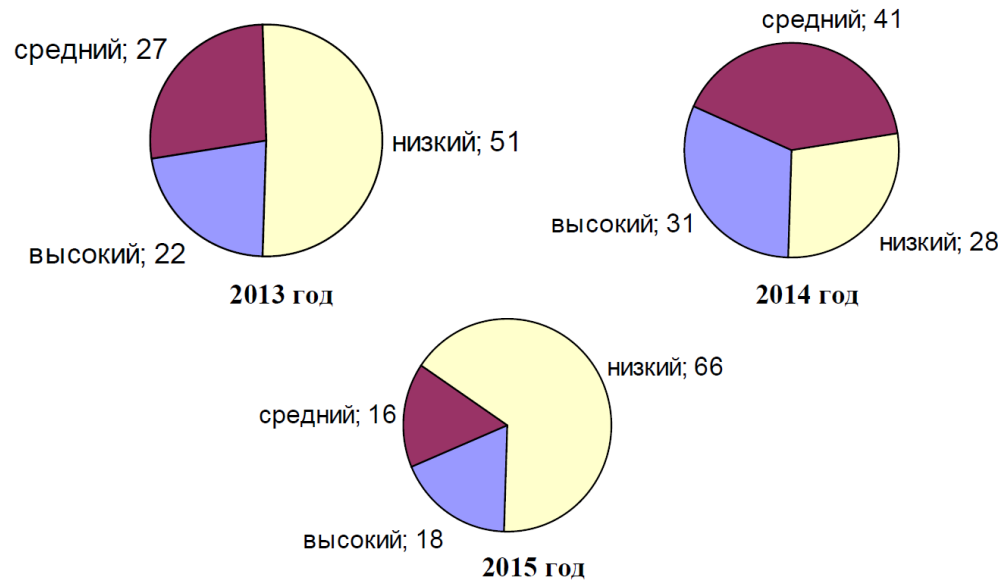

Рис. 7. Процентное соотношение уровневых показателей освоения студентали учебной програмлы разных годов выпуска (2013-2015), на основе кластерного анализа методом "Нейронного газа»

Статистический сравнительный анализ качественного выражения полученных процентов по уровням на основе кластерного анализа с помощью критерия Фишера, определил качественное содержание низкого, среднего и высокого уровней. В табл. 5 приводятся расчеты эмпирических значений критерия Фишера, жирным шрифтом выделены статистически значимые значения.

Таблица 5

Статистическое сравнение процентных уровневых показателей по критерию Фишера (

\begin{tabular}{|c|c|c|c|}
\hline $\begin{array}{c}\text { Сравнение } \\
\text { выпускников }\end{array}$ & \multicolumn{2}{|c|}{$\begin{array}{c}\text { Процентные показатели уровней } \\
\text { усвоения учебной программы, (\%) }\end{array}$} & Критерий Фишера, $\left(\varphi_{\text {эмn }}\right)$ \\
\hline \multicolumn{4}{|c|}{ Высокий уровень } \\
\hline $2013-2014$ & 2 & 31 & $\varphi_{\text {эмn }}=0,94$ \\
\hline $2014-2015$ & 31 & 18 & $\varphi_{\text {эмn }}=1,43$ \\
\hline $2013-2015$ & 22 & 18 & $\varphi_{\text {э.Mn }}=0,66$ \\
\hline \multicolumn{4}{|c|}{ Средний уровень } \\
\hline $2013-2014$ & 27 & 41 & $\varphi_{\text {эми }}=1,38$ \\
\hline $2014-2015$ & 41 & 16 & $\varphi_{\text {эмn }}=2,8$ \\
\hline $2013-2015$ & 27 & 16 & $\varphi_{\text {э.Mn }}=1,76$ \\
\hline \multicolumn{4}{|c|}{ Низкий уровень } \\
\hline $2013-2014$ & 51 & 28 & $\varphi_{\text {эмn }}=2,63$ \\
\hline $2014-2015$ & $2 \varepsilon$ & 66 & $\varphi_{\text {әмп }}=3,79$ \\
\hline $2013-2015$ & 51 & 66 & $\varphi_{э м n}=1,59$ \\
\hline
\end{tabular}

Из табл. 5 видно, что высокий уровень одинаково высок в качественном выражении во всех группах испытуемых студентов. Средний уровень обнаружил разные качественные характеристики. У студентов 2013 и 2014 года выпуска на среднем уровне различий нет. Однако в сравнении с 2015 годом выпуска, у

\section{Baikal Research Journal}


студентов 2014 года выпуска средний уровень усвоения учебной программы качественно лучше, а сравнение процентов среднего уровня выпускников 2013 и 2015 показало более качественные характеристики у студентов выпуска 2013 года. И так как процентные показатели студентов 2013 и 2014 года не имеют статистических различий, то мы можем говорить о том, что студенты среднего уровня 2015 года выпуска хуже всех остальных освоили учебную программу.

Анализ показателей низкого уровня освоения учебной программы студентами также обнаружил статистические различия. Студенты 2013 и 2015 года выпуска различий не обнаружили. Однако их показатели низкого уровня оказались качественно хуже показателей низкого уровня выпускников 2014 года. Из этого следует, что студенты 2014 года гораздо лучше выглядят, находясь на низком уровне усвоения учебной программы. Таким образом, обобщая все статистические значения критерия Фишера можно заключить, что по качеству подготовки студентов на факультете ФИТМиФ лучшим среди обследованных студенческих групп, оказался выпуск 2014 года.

После апробирования данного метода и анализа результатов, мы пришли к выводу, что развитие специальных способностей студентов в соответствующей профессиональной подготовке очень актуально, об этом говорят показатели полученных кластеров. На фоне активной работы педагогического коллектива по организации учебного процесса идет колоссальное снижение качества освоения студентами информационных технологий. Таким образом, данный метод мониторинга и первичной диагностики испытуемых позволяет отсортировать требуемый контингент испытуемых для дальнейшего исследования специальных способностей студентов к овладению информационными технологиями, а также выявляет студентов-аутсайдеров, которым требуется пристальное внимание со стороны педагогов в процессе учебной деятельности.

\section{Список использованной литературы}

1. Журавлева Г. П. Российская наука в новых условиях текущего столетия / Г. П. Журавлева, М. П. Рачков // Экономика и управление. - 2013. - № 6 (92). - С. 52-56.

2. Тоффлер Э. Шок будущего / Э. Тоффлер. - М. : АСТ, 2004. - 557 с.

3. Тихомиров В. П. Качественное образование в информационном обществе, основанном на знаниях. Стратегическая программа развития для России / В. П. Тихомиров // Экономика, статистика и информатика. Вестник УМО. - 2008. - № 1. - С. 5-9.

4. Каткова Е. Н. Актуальные вопросы психологии программирования и теоретические противоречия в обосновании содержания учебного стандарта третьего поколения / Е. Н. Каткова, Г. П. Жиганова // Новая наука: Теоретический и практический взгляд. 2015. - № 5-3. - С. 84-89.

5. Рябова Е. Н. Российское образование в контексте теорий информационного общества / Е. Н. Рябова // В мире научных открытий. - 2010. - № 1-3. - С. 73-79.

6. Комарова А. А. Формирование компетенций при преподавании дисциплины «Информационные технологии в специальном образовании" / А. А. Комарова // Дискуссия. 2013. - Вып. № 3 (33). - С. 111-115.

7. Теплов Б. М. Проблемы индивидуальных различий / Б. М. Теплов. - М.: Изд-во Академии педагогических наук РСФСР, 1961. - 535 с.

8. Зайцева О. Б. Формирование информационной компетентности будущих учителей средствами инновационных технологий : автореф. дис. ... канд. пед. наук / О. Б. Зайцева. - Брянск, 2002. - 19 с.

9. Семёнов А. Л. Роль информационных технологий в общем среднем образовании / А. Л. Семёнов. - М., 2000. - 205 с.

10. Тришина С. В. Информационная компетентность как педагогическая категория [Электронный ресурс] / С. В. Тришина // Эйдос. - 2005. - Режим доступа: http://www. eidos.ru/journal/2005/0910-11.htm.

\section{Baikal Research Journal}


11. Грибан О. Н. Составляющие понятия «информационная компетенция» / О. Н. Грибан. - Режим доступа: http://griban.ru/blog/18-sostavljajuschie-ponjatija-informacionnajakompetencija.html.

12. Шмакова В. А. Структура способностей к учебной деятельности в младшем школьном возрасте и динамика их развития : автореф. дис. ... канд. психолог. наук : 19.00.13/ В. А. Шмакова. - СПб., 2001. - 18 с.

13. Волкова Е. В. Развитие ментальных структур как основы специальных способностей : дис. ... д-ра психолог. наук : 19.00.13 / Е. В. Волкова. - М., 2011. - 333 с.

14. Регуш Л. А. Психология прогнозирования: способность, ее развитие и диагностика / Л. А. Регуш. - Киев : Вища школа, 1997. - 88 с.

15. Каткова Е. Н. Влияние комбинаторных способностей студентов физико-математического факультета на эффективность решения задач, моделирующих нестандартные ситуации / Е. Н. Каткова // Исследование феномена психологической безопасности личности в условиях социально-экономической нестабильности : монография / под общ. ред. Е. В. Опеваловой. - Комсомольск-на-Амуре : Изд-во Комсом. н/А. гос. пед. ун-та, 2006. - 331 с.

16. Каткова Е. Н. Развитие комбинаторных способностей детей дошкольного возраста : автореф. дис. ... канд. психолог. наук : 19.00.13 / Е. Н. Каткова. - Хабаровск, 2005. — 23 с.

17. Каткова Е. Н. Комбинаторные способности человека как основа предпринимательской деятельности / Е. Н. Каткова // Аудит и финансовый анализ. — 2012. — № 4. С. $355-359$.

18. Каткова Е. Н. Развитие комбинаторных способностей дошкольников и перспективы дальнейшего изучения комбинаторных способностей человека в науке / Е. Н. Каткова // Наука и образование / гл. ред. О. Н. Широков. - Чебоксары : Интерактив плюс, 2014. C. 334-357.

19. Subbotin A. Растущий нейронный газ на языке программирования [Электронный pecypc] / A. Subbotin // MQL5. - Режим доступа: https://www.mql5.com/ru/articles/163 (дата обращения: 05.10.2016).

20. Прикладная статистика: Классификация и снижение размерности / С. А. Айвазян [и др.]. - М. : Финансы и статистика, 1989. - 607 с.

21. Мендель И. Д. Кластерный анализ / И. Д. Мендель. - М. : Финансы и статистика, 1988. - 176 c.

22. Суходолов А. П. Системный анализ, моделирование. Математическое моделирование / А. П. Суходолов, В. А. Маренко. - Иркутск : Изд-во БГУ, 2018. - 144 с.

\section{References}

1. Zhuravleva G. P., Rachkov M. P. Russian Science: Facing New Conditions in the Present Century. Ekonomika $i$ upravlenie = Economics and Management, 2013, no. 6 (92), pp. 52-56. (In Russian).

2. Toffler A. Future shock. New York, 1970. 541 p. (Russ. ed.: Toffler A. Shok budushchego. Moscow, AST Publ., 2004. 557 p.).

3. Tikhomirov V. P. Quality education in information society based on knowledge. Strategic Development Program for Russia. Ekonomika, statistika i informatika. Vestnik UMO= Economics, Statistics and Informatics. Bulletin of AMA, 2008, no. 1, pp. 5-9. (In Russian).

4. Katkova E. N., Zhiganova G. P. Topical issues of programming psychology and theoretical contradictions in substantiating the content of the third generation educational standard. Novaya nauka: Teoreticheskii i prakticheskii vzglyad = New Science: Theoretical and Practical View, 2015, no. 5-3, pp. 84-89. (In Russian).

5. Ryabova E. N. Russian education in terms of information society theories. $V$ mire nauchnykh otkrytii $=$ Siberian Journal of Life Sciences and Agriculture, 2010, no. 1-3, pp. 7379. (In Russian).

6. Komarova A. A. Competence formation in teaching of the discipline «Informational technologies in special education». Diskussiya = Discussion, 2013, no. 3 (33), pp. 111-115. (In Russian).

7. Teplov B. M. Problemy individual'nykh razlichii [Problems of individual differences]. Moscow, Akademiya pedagogicheskikh nauk RSFSR Publ., 1961. 535 p.

8. Zaitseva O. B. Formirovanie informatsionnoi kompetentnosti budushchikh uchitelei sredstvami innovatsionnykh tekhnologii. Avtoref. Kand. Diss. [Formation of information of future

\section{Baikal Research Journal}


teachers' competence by means of innovative technologies. Cand. Diss. Thesis]. Bryansk, 2002. $19 \mathrm{p}$.

9. Semenov A. L. Rol' informatsionnykh tekhnologii v obshchem srednem obrazovanii [Role of information technology in general secondary education]. Moscow, 2000. 205 p.

10. Trishina S. V. Information competence as a pedagogical category. Eidos = Eydos, 2005. Available at: http://www.eidos.ru/journal/2005/0910-11.htm. (In Russian).

11. Griban O. N. Components of «information competence» concept. Available at: http:// griban.ru/blog/18-sostavljajuschie-ponjatija-informacionnaja-kompetencija.html. (In Russian).

12. Shmakova V. A. Struktura sposobnostei $k$ uchebnoi deyatel'nosti v mladshem shkol'nom vozraste i dinamika ikh razvitiya. Avtoref. Kand. Diss. [Structure of educational activity abilities in primary school age and dynamics of their development. Cand. Diss. Thesis]. Saint-Petersburg, 2001. $18 \mathrm{p}$.

13. Volkova E. V. Razvitie mental'nykh struktur kak osnovy spetsial'nykh sposobnostei. Dr. Diss. [Development of mental structures as a basis of special abilities. Dr. Diss.]. Moscow, 2011. $333 \mathrm{p}$.

14. Regush L. A. Psikhologiya prognozirovaniya: sposobnost', ee razvitie i diagnostika [Psychology of forecasting: ability, its development and diagnostics]. Kiev, Vishcha shkola Publ., 1997. $88 \mathrm{p}$.

15. Katkova E. N. Impact of combinatorial abilities of students studying at Department of Physics and Mathematics on the efficiency of solving problems that model non-standard situations. In Opevalova E. V. (ed.). Issledovanie fenomena psikhologicheskoi bezopasnosti lichnosti $v$ usloviyakh sotsial'no-ekonomicheskoi nestabil'nosti [Research on phenomenon of psychological security of an individual in terms of socio-economic instability]. Komsomol'sk-na-Amure state pedagogical university Publ., 2006. 331 p. (In Russian).

16. Katkova E. N. Razvitie kombinatornykh sposobnostei detei doshkol'nogo vozrasta. Avtoref. Kand. Diss. [Development of combinatorial abilities of preschool children. Cand. Diss. Thesis]. Khabarovsk, 2005. 23 p.

17. Katkova E. N. Personal combinatorial abilities as a basis of entrepreneurial activity. $A u$ dit $i$ finansovyi analiz = Audit and Financial Analysis, 2012, no. 4, pp. 355-359. (In Russian).

18. Katkova E. N. Development of combinatorial abilities of preschool children and prospects for further study of human combinatorial abilities in science. In Shirokov O. N. (ed.). Nauka $i$ obrazovanie [Science and Education]. Cheboksary, Interaktiv plyus Publ., 2014, pp. 334-357. (In Russian).

19. Subbotin A. The growing neural gas in the programming language. $M Q L 5$. Available at: https://www.mq15.com/ru/articles/163. (In Russian).

20. Aivazyan S. A., Bukhshtaber V. M., Enyukov I. S., Meshalkin L. D. Prikladnaya statistika: Klassifikatsiya i snizhenie razmernosti [Applied Statistics: Classification and Dimension Reduction]. Moscow, Finansy i statistika Publ., 1989. 607 p.

21. Mendel' I. D. Klasternyi analiz [Cluster analysis]. Moscow, Finansy i statistika Publ., 1988. $176 \mathrm{p}$.

22. Sukhodolov A. P., Marenko V. A. Sistemnyi analiz, modelirovanie. Matematicheskoe modelirovanie [System Analysis, Modeling. Mathematical Modeling]. Irkutsk, Baikal State University Publ., 2018. 144 p.

\section{Информация об авторах}

Каткова Елена Николаевна - доцент, кандидат психологических наук, кафедра психологии образования, Институт педагогики и психологии, Амурский гуманитарно-педагогический государственный университет, 681000, г. Комсомольск-на-Амуре, ул. Кирова, 17, корп. 2, e-mail: elenakatkova@mail.ru.

Жиганова Галина Петровна - доцент, кафедра информационных систем, компьютерных технологий и физики, факультет информационных технологий, математики и физики, Амурский гуманитарно-педагогический государственный университет, 681000, г. Комсомольск-на-Амуре, ул. Кирова, 17, корп. 2, e-mail: galina_239@mail.ru.

Саяпина Анна Александровна - магистрантка 2-го года обучения, кафедра психологии образования, Институт педагогики и психологии, Амурский гуманитарно-педагогический государственный университет, 681000, г. Комсомольск-на-Амуре, ул. Кирова, 17, корп. 2 , e-mail: iva-anna.mix@mail.ru.

\section{Baikal Research Journal}

электронный научный журнал Байкальского государственного университета 


\section{Authors}

Elena N. Katkova - PhD in Psychology, Associate Professor, Chair of Educational Psychology, Institute of Pedagogy and Psychology, Amur Humanitarian Pedagogical State University, 17 Kirov St., 681000, Komsomolsk-on-Amur, e-mail: elenakatkova@mail.ru.

Galina P. Zhiganova - Associate Professor, Chair of Information Systems, Computer Technologies and Physics, Amur Humanitarian Pedagogical State University, 17 Kirov St., 681000, Komsomolsk-on-Amur, e-mail: galina_239@mail.ru.

Anna A. Sayapina - Master Degree Studēnt, Chair of Educational Psychology, Institute of Pedagogy and Psychology, Amur Humanitarian Pedagogical State University, 17 Kirov St., 681000, Komsomolsk-on-Amur, e-mail: iva-anna.mix@mail.ru.

\section{Для цитирования}

Каткова Е. Н. Вопросы разработки методов диагностики специальных способностей к овладению информационными технологиями / Е. Н. Каткова, Г. П. Зћиганова, А. А. Саяпина // Baikal Research Journal. - 2018. - T. 9, № 1. — DOI : 10.17150/2411$\underline{6262.2018 .9(1) .12 .}$

\section{For Citation}

Katkova E. N., Zhiganova G. P., Sayapina A. A. Issues of Developing Diagnostic Methods for Special Abilities of Mastering Information Technologies. Baikal Research Journal, 2018, vol. 9, no. 1. DOI: 10.17150/2411-6262.2018.9(1).12. (In Russian).

\section{Baikal Research Journal}

